\title{
Abundant mesopelagic fauna at oceanic high latitudes
}

\author{
Lia Siegelman-Charbit ${ }^{1,2}$, Benjamin Planque ${ }^{1,3, *}$ \\ ${ }^{1}$ Institute of Marine Research, PO Box 6404, 9294 Tromsø, Norway \\ ${ }^{2}$ Université Pierre et Marie Curie, 4 place Jussieu, 75005 Paris, France \\ ${ }^{3}$ Hjort Centre for Marine Ecosystem Dynamics, PO Box 1870 Nordnes, 5817 Bergen, Norway
}

\begin{abstract}
The presence of a dense layer of organisms in the mesopelagic zone is a ubiquitous feature of the world oceans, and these organisms may constitute a major component of marine biomass worldwide. Many mesopelagic organisms perform light-dependent diel vertical migration. It has been hypothesised that extreme light regimes encountered at high latitudes may disturb these migration patterns and thereby limit the northern expansion of mesopelagic fauna into the Arctic. Using hydroacoustic data collected during 4 surveys conducted in the open Norwegian Sea during the summer season, we evaluated if the key features of mesopelagic fauna reported worldwide (high density and diel vertical migration) are also observed in the high latitudes of the Northeast Atlantic. The results confirm that the high-latitude Northeast Atlantic hosts a high density of mesopelagic fauna which performs daily migration patterns similar to those reported in other regions. They also support the limiting effect of photoperiod on its potential biomass. These results stress the need for thorough studies on the abundance, biodiversity and trophic ecology of the mesopelagic fauna in this region.
\end{abstract}

KEY WORDS: Arctic $\cdot$ High latitudes $\cdot$ Hydroacoustics $\cdot$ Mesopelagic $\cdot$ Norwegian Sea $\cdot$ Sub-Arctic

\section{INTRODUCTION}

The presence of a dense layer of animals between 200 and $1000 \mathrm{~m}$ is a ubiquitous feature of the world oceans. Although most fisheries operate on continental shelves and slopes, where biological productivity is greater, the biomass of fish and invertebrates in the mesopelagic layer may vastly exceed world catches. Early estimates of the global biomass of mesopelagic fish suggested a billion metric tonnes (Gjøsæeter \& Kawaguchi 1980). However, these were based on midwater trawling, which underestimates biomass substantially (Kaartvedt et al. 2012). Recent estimates are on the order of 10 billion metric tonnes (Irigoien et al. 2014), i.e. a hundred times more than present annual global fish landings. This estimate does not include the biomass of animal groups other than fish in the mesopelagic zone. Uncertainty in mesopelagic fish biomass estimates from hydroacoustic studies remains colossal (Davison et al. 2015), but right or

${ }^{*}$ Corresponding author: benjamin.planque@imr.no wrong, these biomass estimates show that a major component of the ocean ecosystems has not yet been significantly studied. Mesopelagic organisms are characterised by vertical distribution patterns, and most of the mesopelagic fauna performs light-dependent diel vertical migration (DVM) (Watanabe et al. 1999, Angel \& Pugh 2000, Kaartvedt 2008). Even though this is a remarkable feature of mesopelagic organisms, species-specific patterns remain largely unknown (Brodeur \& Yamamura 2005). The possible extension of boreal species into the Arctic basin following warming conditions in the ocean has been hypothesised for some commercial species (Hollowed et al. 2013, Wisz et al. 2015). However, the light regime specific to regions beyond the Arctic Circle may prevent mesopelagic species from migrating further north, since summer continuous light and winter continuous darkness disturb light-dependent vertical migration of mesopelagic species (Kaartvedt 2008). Many mesopelagic species perform DVM into the

(C) Institute of Marine Research, Norway 2016. Open Access under Creative Commons by Attribution Licence. Use, distribution and reproduction are unrestricted. Authors and original publication must be credited. Publisher: Inter-Research - www.int-res.com 
epipelagic layer in their quest for food before migrating down several hundred meters to their daytime depths, and light has been found to be a controlling factor for migrators who optimise feeding while minimising visibility to predators (Salvanes 2004). Few investigations of the mesopelagic fauna have been conducted in high latitudes in comparison to midand tropical latitudes, and considerable knowledge gaps remain regarding biomass and DVM patterns of the mesopelagic fauna in oceanic high latitudes. To date, high-latitude field studies have predominantly been conducted in fjords, and they have shown that migrating organisms comprise high biomasses of mesopelagic fish (Giske et al. 1990, Baliño \& Aksnes 1993) or krill (Onsrud \& Kaartvedt 1998). There is comparatively little information about the distribution and abundance of the mesopelagic fauna in the open ocean at high latitudes, and it is assumed that the extreme light regime may be unfavourable to many mesopelagic species, in particular those performing DVM. The goal of the present study is to evaluate if the key features of mesopelagic fauna (high abundance and DVM) are also observed in the high latitudes of the Northeast Atlantic and to determine

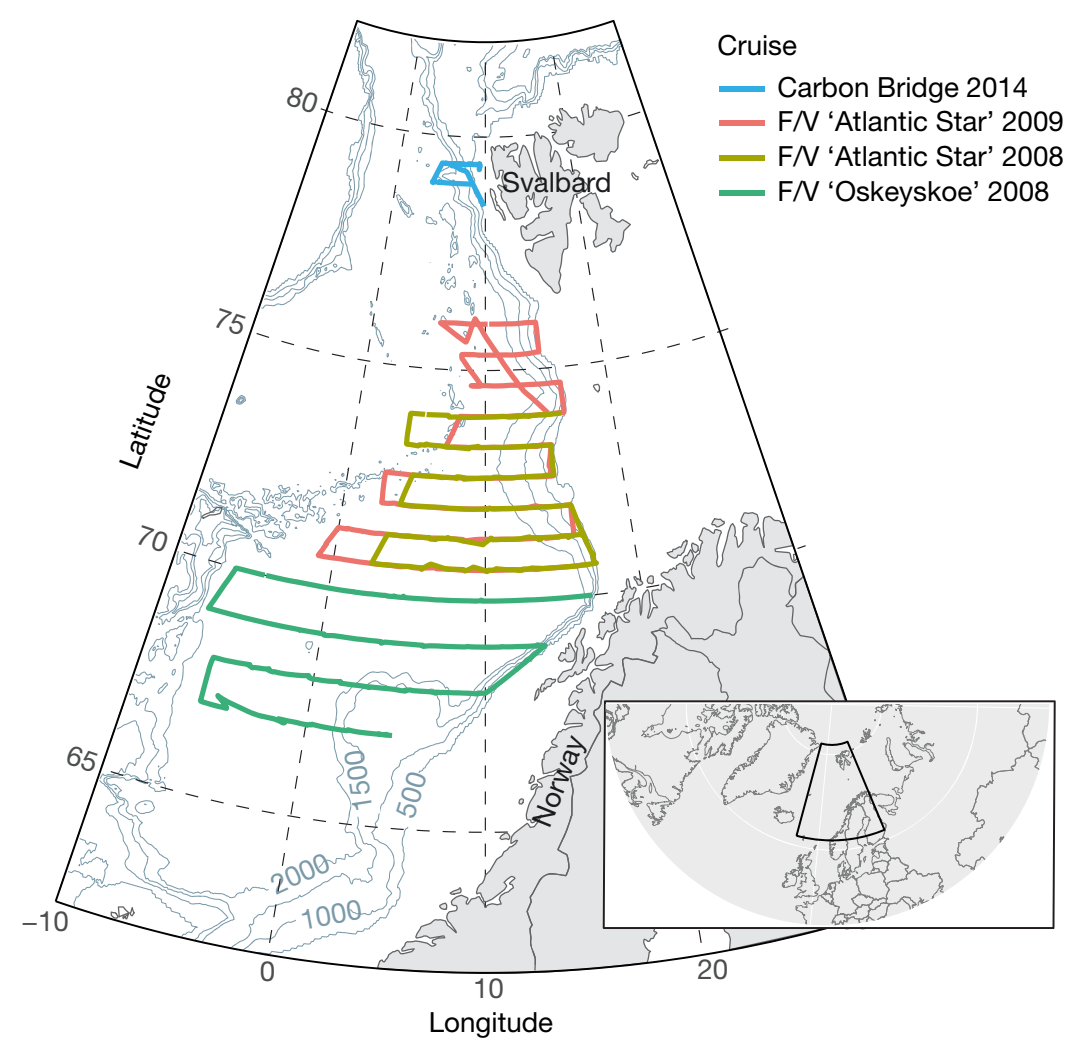

Fig. 1. Locations of the hydroacoustic transects registered during 4 cruises in the Norwegian Sea and to the west of Svalbard during the summer between 2008 and 2014. The inset indicates the location of the study area in the North Atlantic Ocean whether a dense mesopelagic layer can be observed under the extreme summer light regime in this region. For this purpose, we analysed hydroacoustic data collected during 4 surveys conducted in the open Norwegian Sea during the summer season.

\section{MATERIALS AND METHODS}

\section{Data acquisition}

Hydroacoustic data were collected during 4 cruises conducted in the Norwegian Sea and to the west of Svalbard during summer, covering in total more than 7700 nautical miles (Fig. 1). In August 2008, the F/V 'Atlantic Star' (Norway) and the F/V 'Osveyskoe' (Russia) jointly surveyed the Norwegian Sea. The joint survey was initiated by the North East Atlantic Fisheries Commission and coordinated by ICES with the aim of monitoring the distribution and abundance of beaked redfish Sebastes mentella primarily inhabiting the mesopelagic zone (ICES 2008). In August 2009, the Norwegian survey was repeated by the F/V 'Atlantic Star'. In May 2014, the R/V 'Helmer Hansen' conducted a cruise to the northwest of Svalbard as part of the Carbon Bridge project (University of Tromsø, Norway). During each cruise, fisheries hydroacoustic measurements were made using a $38 \mathrm{kHz}$ hull-mounted SIMRAD EK 60 echosounder. The ping rate was adjusted to allow registrations down to depths of 750 to $1000 \mathrm{~m}$, and the calibration was done following a standard protocol (Foote et al. 1987).

\section{Echogram interpretation}

The surface backscattering strength $\left(s_{\mathrm{A}}\right)$ was used to quantify the acoustic energy in the deep scattering layer (DSL) (Simmonds \& MacLennan 2005). Acoustic energy was allocated to 3 distinct categories. The first 2 categories correspond to biological signals above and within the DSL. This delimitation, which relies on a biological rather than a strict bathymetric approach, was complemented by bathymetric constraints. The DSL was considered to be mesopelagic when it was located between 200 and $800 \mathrm{~m}$ depth, and the biological signal that registered out- 
side the DSL was assigned to the epipelagic layer when it was shallower than $400 \mathrm{~m}$. Data acquisition is limited to a maximal depth of $800 \mathrm{~m}$, below which instrumental noise becomes too dominant. The third category corresponds to the non-biological signal induced by e.g. instrumental noise, surface bubbles or a false bottom echo. A volume backscattering strength $\left(s_{\mathrm{V}}\right)$ threshold level of $-82 \mathrm{~dB}$ was applied for all registrations. Data were analysed using the software Large Scale Survey System (Korneliussen et al. 2006). An illustration of echogram interpretation is shown in Fig. 2.

\section{Vertical migration depth}

The upper envelope of the DSL was used as a proxy for vertical migration depth. Daily changes in the depth of the upper envelope reflect DVM patterns for migrating organisms, while these are little influenced by the mean residence depth of non-migrating organisms. This upper envelope depth was defined using the 12.5th $s_{\mathrm{A}}$ percentile and corresponds to the depth where $12.5 \%$ of $s_{\mathrm{A}}$ is located above and $87.5 \%$ is located below. An illustration of the changes in the depth of the upper envelope of the DSL is shown in Fig. 3b.

\section{Solar elevation and photoperiod}

Solar elevation angle, in degrees, was computed with the solar position algorithm by Reda \& Andreas (2008). The solar elevation is zero when the sun is at the horizon. It is positive when the sun is above the horizon $(+90=$ zenith $)$ and negative when it is below ( $-90=$ nadir).

To characterise day-night cycles, the following photoperiod coefficient was computed:

$$
r_{\mathrm{dn}}=\left(h_{\mathrm{d}}-h_{\mathrm{n}}\right) / 24
$$

where $h_{\mathrm{d}}$ is the number of hours when the sun is above the horizon, and $h_{\mathrm{n}}$ is the number of hours when the sun is below the horizon. The index value varies between -1 (full night) and +1 (full day). Solar elevation and photoperiod were computed to

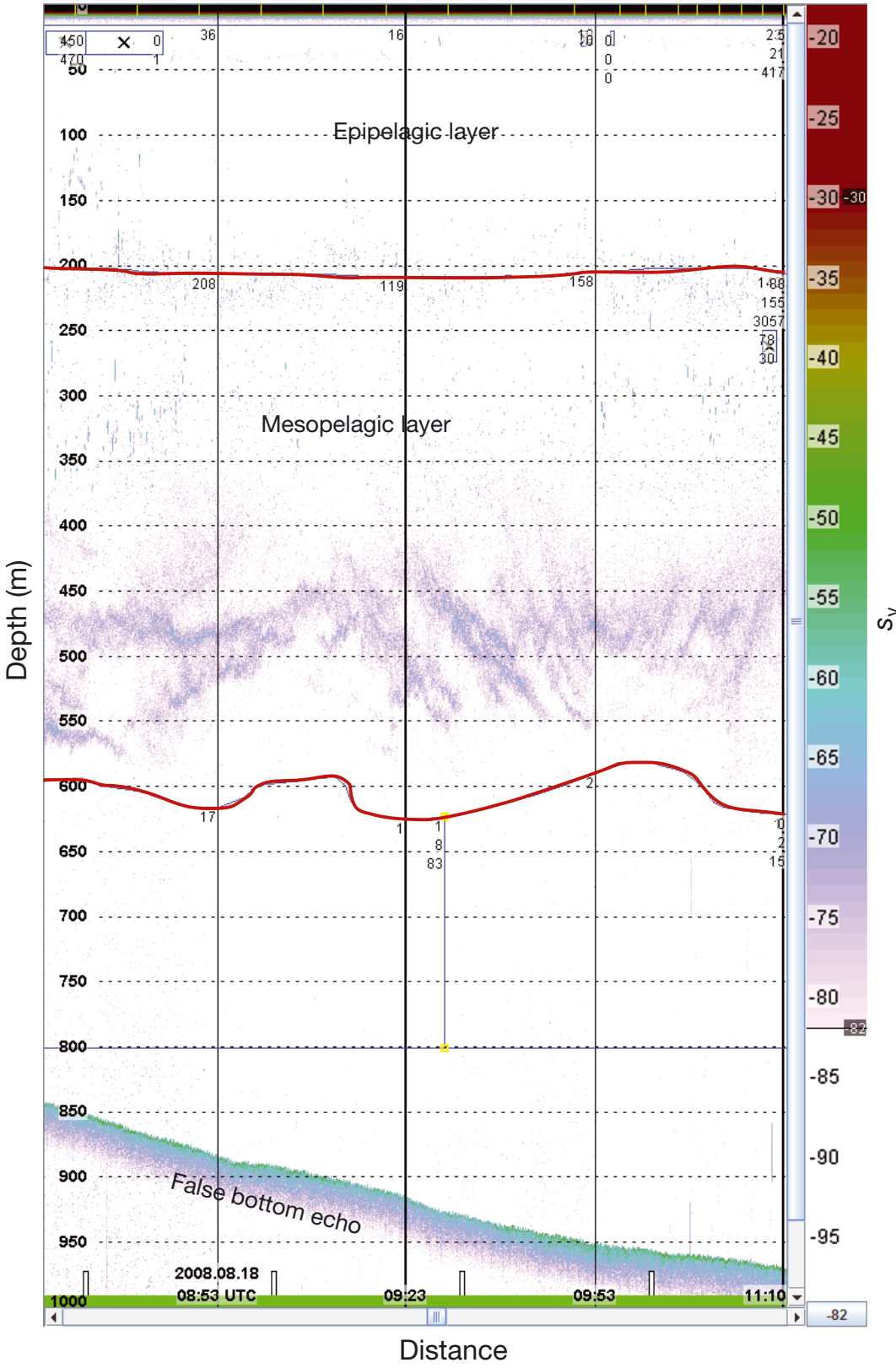

Fig. 2. Hydroacoustic registrations (echograms) during the F/V 'Atlantic Star' cruise in the central Norwegian Sea in 2008 over a distance of 2 nautical miles and from the surface down to $1000 \mathrm{~m}$ depth. Intensity of reflected energy per unit volume (volume backscattering strength, $s_{\mathrm{V}}$ ) is indicated by the colour scale. Red lines display the upper and lower limits of the deep scattering layer

characterise the light regime for every nautical mile. An illustration of solar elevation is shown in Fig. 3a.

\section{Epipelagic versus mesopelagic}

Acoustic energies were compared in the epi- and mesopelagic layers by calculating the ratio of the 

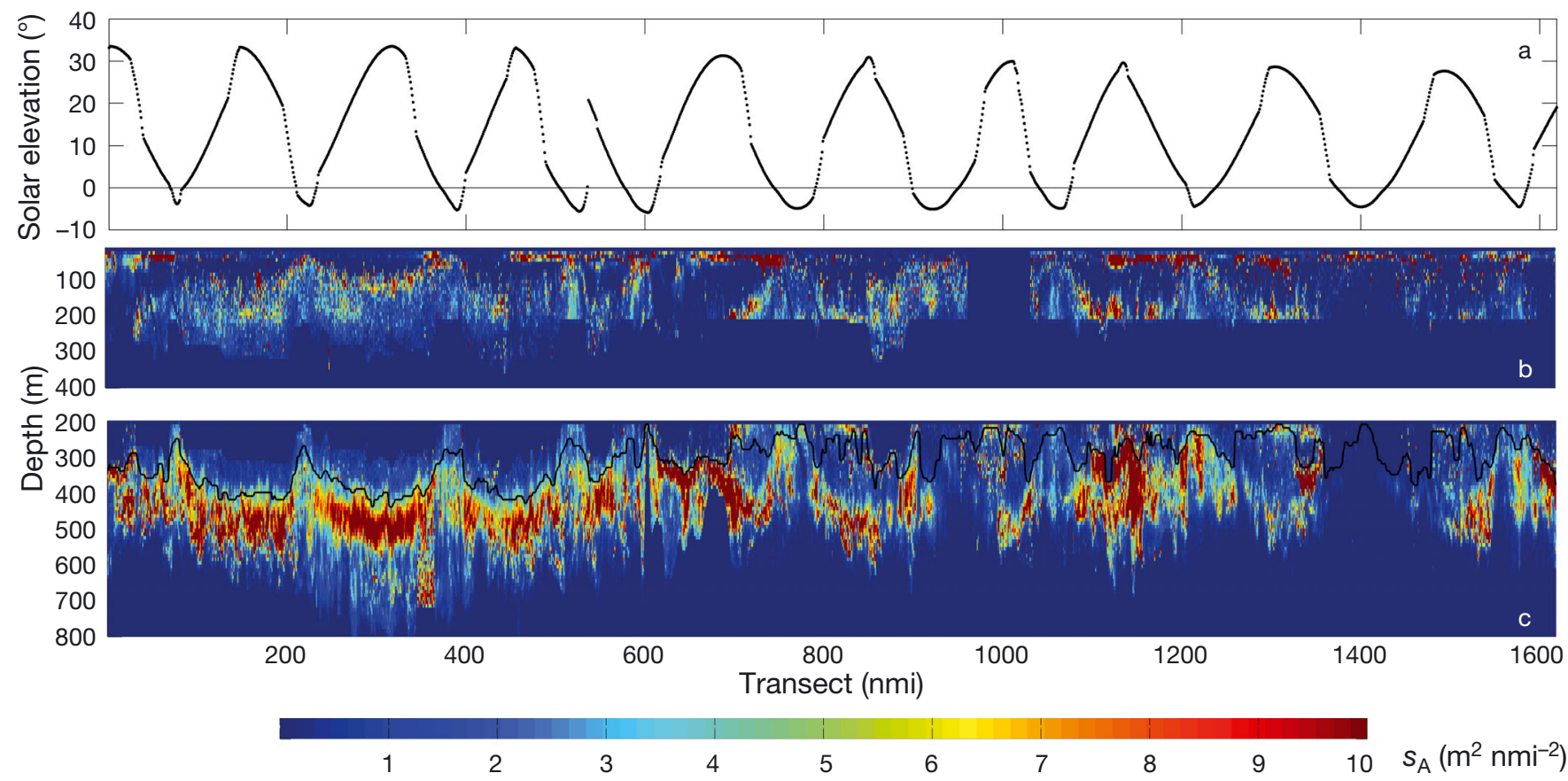

Fig. 3. (a) Solar elevation angle, (b) surface backscattering strength $\left(s_{\mathrm{A}}\right)$ allocated to the epipelagic layer and (c) $s_{\mathrm{A}}$ allocated to the mesopelagic layer during the F/V 'Atlantic Star' survey in 2008. The thin dark line in the mesopelagic transect (c) signals the upper 12.5th percentile of $s_{\mathrm{A}}$ for every nautical mile and is used as a proxy for the upper limit of the deep scattering layer

average $s_{\mathrm{A}}$ in each layer for each cruise. An illustration of acoustic energy in the epi- and mesopelagic layers is shown in Fig. 3b,c.

\section{Depth versus solar elevation}

To assess the possible link between light regime and migrating behaviour of mesopelagic organisms, the vertical migration depth was plotted against solar elevation. Under the standard DVM hypothesis, it is expected that the upper limit of the DSL should deepen with increasing solar elevation.

\section{Acoustic energy versus photoperiod}

The acoustic energy in the mesopelagic layer was plotted against the photoperiod coefficient to illustrate the possible influence of the day-night cycle on the abundance of mesopelagic fauna. Under the photoperiod constraint hypothesis (Kaartvedt 2008) and assuming that variations in $s_{\mathrm{A}}$ reflect variations in biomass, it is expected that $s_{\mathrm{A}}$ should decline as the photoperiod index approaches extreme values (i.e. full day or full night).

Numerical analyses were conducted using the software Matlab.

\section{RESULTS}

There was generally more acoustic energy in the mesopelagic than in the epipelagic layer. This was observed in all surveys (Table 1). Whilst the mean hydroacoustic energy in the epipelagic layer can be highly variable and does not seem to follow any clear geographical pattern, the energy in the mesopelagic layer appears to decrease with increasing latitude. There was 3.5 times more acoustic energy recorded at low latitudes ( $\mathrm{F} / \mathrm{V}$ 'Osveyskoe' cruise) than at the highest (Carbon Bridge cruise).

Following the expected DVM patterns, the upper limit of the mesopelagic layer deepened as solar elevation increased (Fig. 4). This is particularly evident for solar elevations between -20 and $10^{\circ}$, which correspond to crepuscular periods. For greater solar elevations (between 10 and $40^{\circ}$ ), a deepening of the mesopelagic layer was also observed but with lower amplitude.

There does not appear to be a clear relationship between the mean acoustic energy recorded in the mesopelagic layer and the photoperiod (Fig. 5). However, it appears that the maximum recorded acoustic energy in the surveys declined as the photoperiod index increased towards extreme (i.e. full daylight) values. This can be indicative of the photoperiod being a limiting factor for mesopelagic biomass. 
Table 1. Average acoustic energy per square nautical mile (surface backscattering strength, in $\mathrm{m}^{2} \mathrm{nmi}^{-2}$ ) recorded in the epi- and mesopelagic layers during 4 surveys in the Norwegian Sea and the ratio between these averages

\begin{tabular}{|lcccc|}
\hline Survey & Carbon Bridge & F/V 'Osveyskoe' & F/V 'Atlantic Star' 2009 & F/V 'Atlantic Star' 2008 \\
\hline Epipelagic & 18 & 87 & 71 & 116 \\
Mesopelagic & 61 & 215 & 140 & 133 \\
Ratio (mesopelagic:epipelagic) & 3.4 & 2.5 & 2.0 & 1.2 \\
\hline
\end{tabular}

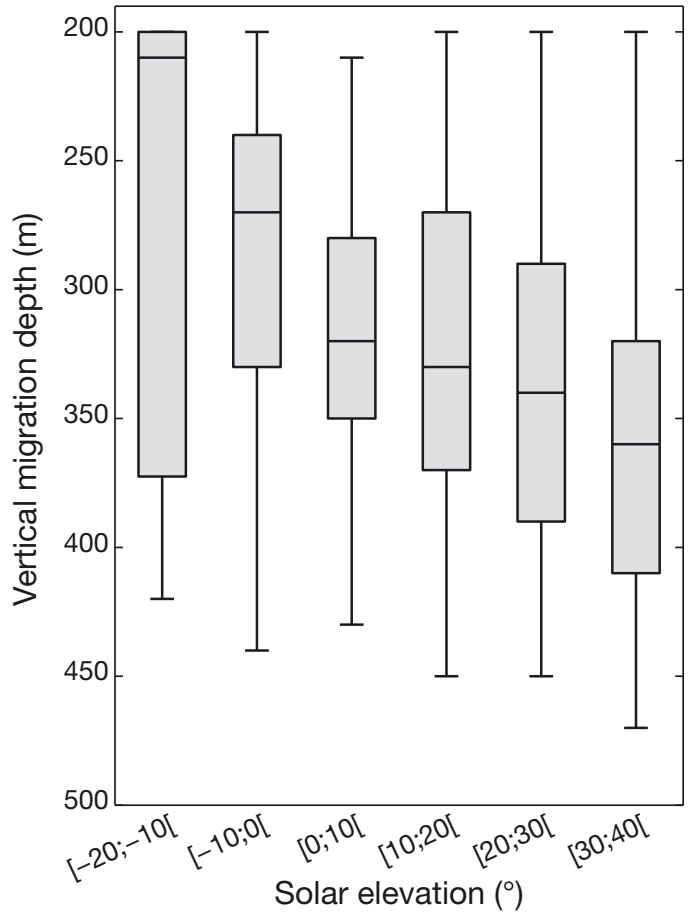

Fig. 4. Depth of the upper limit of the deep scattering layer as a function of solar elevation. Central lines in the boxplots correspond to median depth, box extremities correspond to 1st and 3rd quartiles and whiskers extend to the most extreme data points

\section{DISCUSSION AND CONCLUSIONS}

The measured acoustic energy in the Norwegian Sea suggests the presence of a dense layer of mesopelagic fauna in oceanic high latitudes. Although there was no dedicated sampling to quantify the species composition, biomass and abundance, the high levels of acoustic energy recorded suggest that the biomass in the mesopelagic layer may exceed that of the epipelagic layer, a pattern similar to that reported for tropical and subtropical waters by Gjøsæter \& Kawaguchi (1980) and Irigoien et al. (2014).

Changes in the depth of the upper limit of the DSL, coupled with solar elevation, confirm the hypothesis of light-driven DVM patterns. This is in agreement with previously reported patterns for mesopelagic

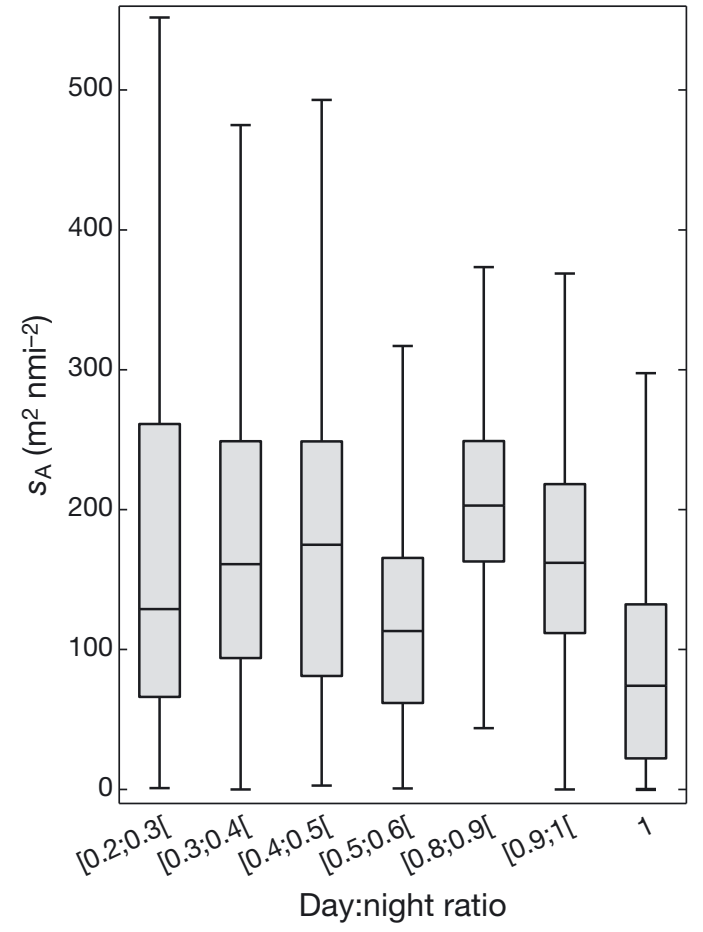

Fig. 5. Backscattered energy per unit area (surface backscattering strength, $s_{\mathrm{A}}$ ) as a function of the day:night ratio; a ratio of 1 is when the sun is $24 \mathrm{~h}$ above the horizon, and a ratio of zero is when the sun is $12 \mathrm{~h}$ above and $12 \mathrm{~h}$ below the horizon. Central lines in the boxplots correspond to median depth, box extremities correspond to 1st and 3rd quartiles and whiskers extend to the most extreme data points

fishes in the Norwegian Sea (Salvanes 2004), for other micronekton taxa in the Northeast Atlantic (Angel \& Pugh 2000) and for myctophid fishes in the western North Pacific (Watanabe et al. 1999). However, these migratory behaviours may only concern a fraction of the mesopelagic fauna, and the distinction between migration types (i.e. midwater migrant, semimigrant and passive migrant; Brodeur \& Yamamura 2005) was not possible given the available data. Although the present analysis restricts the analysis of DVM patterns to waters deeper than $200 \mathrm{~m}$, it is noticeable (Fig. 3b,c) that the DSL is predominantly located at mesopelagic depth also at night and seldom penetrates the epipelagic zone, in contrast to what is observed in other areas of the world ocean. 
The mean acoustic energy of the mesopelagic fauna does not appear to be directly linked to the photoperiod. However, extreme high $s_{\mathrm{A}}$ values appear to decrease as the light regime tends towards a full day period. This suggests that while the actual abundance of mesopelagic fauna may be controlled by numerous factors other than photoperiod, the maximum attainable abundance could be constrained by the photoperiod. This is in agreement with the photoperiod constraint hypothesis introduced by Kaartvedt (2008). It entails that anticipated effects of ocean warming on the expansion of marine fauna distribution towards Arctic regions (e.g. Cheung et al. 2009) may be countered by the extreme Arctic light regime, which will preclude some of the mesopelagic fauna from migrating northwards.

Aside from the major mesopelagic fish species frequently encountered in the Norwegian Sea such as Maurolicus mülleri, Benthosema glaciale, Arctozenus risso and Argentina silus, the biodiversity of this layer remains largely unknown, and mesopelagic invertebrates such as some euphausiids, decapods, copepods and gelatinous plankton could well represent a more important part of the biodiversity than is commonly acknowledged (Melle et al. 2004). Considerable knowledge gaps still remain regarding trophic interactions within the mesopelagic layer as well as between the mesopelagic layer and shallower and deeper waters (Sutton 2013). The present findings suggest the existence of a dense mesopelagic layer in oceanic high latitudes and call for accurate estimates of the abundance of the mesopelagic fauna in oceanic high latitudes. They also stress the need for thorough studies on the biodiversity of the mesopelagic fauna in this region.

Acknowledgements. The authors thank the captains and cruise leaders of the surveys that form the basis for this study. Marit Reigstad provided access to the Carbon Bridge survey hydroacoustic data. This research was supported by project 14565 of the Institute of Marine Research, Norway.

\section{LITERATURE CITED}

Angel MV, Pugh PR (2000) Quantification of diel vertical migration by micronektic taxa in the northeast Atlantic. Hydrobiologia 440:161-179

Baliño BM, Aksnes DL (1993) Winter distribution and migration of the sound scattering layers, zooplankton and micronekton in Masfjorden, western Norway. Mar Ecol Prog Ser 102:35-50

Brodeur RD, Yamamura O (eds) (2005) Micronekton of the North Pacific. PICES Sci Rep No. 30

Cheung WWL, Lam VWY, Sarmiento JL, Kearney K, Watson

Editorial responsibility: Stylianos Somarakis,

Heraklion, Greece
R, Pauly D (2009) Projecting global marine biodiversity impacts under climate change scenarios. Fish Fish 10: 235-251

> Davison PC, Koslow JA, Kloser RJ (2015) Acoustic biomass estimation of mesopelagic fish: backscattering from individuals, populations, and communities. ICES J Mar Sci 72:1413-1424

Foote KG, Knudsen HP, Vestnes G, MacLennan DN, Simmonds EJ (1987) Calibration of acoustics instruments for fish density estimation: a practical guide. ICES Coop Res Rep 144:1-69

Giske J, Aksnes DL, Baliño BM, Kaartvedt S and others (1990) Vertical distribution and trophic interactions of zooplankton and fish in Masfjorden, Norway. Sarsia 75: 65-82

Gjøsæter J, Kawaguchi K (1980) A review of the world resources of mesopelagic fish. FAO Fish Tech Pap 193, FAO, Rome

Hollowed AB, Planque B, Loeng H (2013) Potential movement of fish and shellfish stocks from the sub-Arctic to the Arctic Ocean. Fish Oceanogr 22:355-370

ICES (2008) Report of the ad hoc group on the international redfish survey in the Norwegian Sea (AGRED). ICES CM 2008/ACOM:63. ICES, Copenhagen

Irigoien X, Klevjer TA, Røstad A, Martinez U and others (2014) Large mesopelagic fishes biomass and trophic efficiency in the open ocean. Nat Commun 5:3271

Kaartvedt S (2008) Photoperiod may constrain the effect of global warming in arctic marine systems. J Plankton Res 30:1203-1206

Kaartvedt S, Staby A, Aksnes DL (2012) Efficient trawl avoidance by mesopelagic fishes causes large underestimation of their biomass. Mar Ecol Prog Ser 456:1-6

Korneliussen RJ, Ona E, Eliassen I, Heggelund Y and others (2006) The large scale survey system - LSSS. In: Proc 29th Scandinavian Symp Phys Acoustics. 29 Jan-01 Feb 2006, Ustaoset

Melle W, Ellersten B, Skjoldal HR (2004) Zooplankton: the link to higher trophic levels. In: Skjoldal HR (ed) The Norwegian Sea ecosystem. Tapir Academic Press, Trondheim, p 137-202

Onsrud MSR, Kaartvedt S (1998) Diel vertical migration of the krill Meganyctiphanes norvegica in relation to physical environment, food and predators. Mar Ecol Prog Ser 171:209-219

Reda I, Andreas A (2008) Solar position algorithm for solar radiation application. Tech Rep NREL/TP-560-34302 (rev). National Renewable Energy Laboratory, Golden, CO

Salvanes AGV (2004) Mesopelagic fish. In: Skjoldal HR, Sætre R, Færnö A, Misund OA, Røttingen I (eds) The Norwegian Sea ecosystem. Tapir Academic Press, Trondheim, p 301-314

Simmonds J, MacLennan D (2005) Fisheries acoustics: theory and practice, 2nd edn. Blackwell Science, Oxford

Sutton TT (2013) Vertical ecology of the pelagic ocean: classical patterns and new perspectives. J Fish Biol 83: 1508-1527

> Watanabe H, Moku M, Kawaguchi K, Ishimaru K, Ohno A (1999) Diel vertical migration of myctophid fishes (family Myctophidae) in the transitional waters of the western North Pacific. Fish Oceanogr 8:115-129

Wisz MS, Broennimann O, Gronkjaer P, Moller PR and others (2015) Arctic warming will promote Atlantic-Pacific fish interchange. Nat Clim Change 5:261-265 